\title{
La licencia comercial prevenida por el artículo 6 de la Ley de Ordenación del Comercio Minorista para la instalacion y apertura de grandes establecimientos
}

\author{
Carlos Navarro del Cacho \\ Profesor Asociado de Derecho Administrativo \\ Universidad de Zaragoza
}

Sumario: 1. EL NACIMIENTO DE LA LICENCIA COMERCIAL. A. Alternativas a la licencia comercial. B. Establecimientos que precisan «licencia comercial». C. ¿Precisa «licencia comercial» la ampliación y la modificación de grandes establecimientos? 2. LA COMPETENCIA DE LAS COMUNIDADES AUTÓNOMAS. 3. LA LEGALIDAD DE LA «LICENCIA COMERCIAL». 4. LA FUNDAMENTACIÓN Y EL TRÁMITE DE LA «LICENCIA COMERCIAL». A. La comprobación de la adecuación de la instalación al equipamiento comercial previamente existente en la zona. B. Los efectos de la instalación sobre la estructura comercial de la zona. C. El informe del Tribunal de Defensa de la Competencia. D. La intervención de las Comisiones Territoriales de Equipamientos Comerciales. E. La «licencia comercial» obtenida por silencio positivo. 5. REFERENCIA A OTRAS AUTORIZACIONES ADMINISTRATIVAS.

\section{EL NACIMIENTO DE LA LICENCIA COMERCIAL}

Una las innovaciones más llamativas, aunque de carácter «relativo», que introdujo la LOCM en el ámbito de la intervención administrativa y que se impuso a la diferenciada regulación establecida por las Comunidades Autónomas (el art. 6.1 es legislación básica, según advierte la DF única de la LOCM) la constituyó la sujeción de la instalación de los grandes establecimientos a la obtención de una - legalmente denominada - «licencia comercial» que, en teoría persigue, de una parte, el comprobar la adecuación de la instalación pretendida al equipamiento comercial previamente existente en la zona afectada y, de otra parte, ponderar los efectos que habrían de derivarse de la instalación en la estructura comercial de dicha zona (art. 6.2, también legislación básica) ${ }^{1}$.

\footnotetext{
1 Desde un punto de vista más amplio, la intervención en la actividad comercial vendria fundamentada, primero, por su afección en la actividad económica nacional; segundo, por razón de defensa de la competencia; tercero, por la necesidad de proteger a consumidores y usuarios y de obtener un equilibrio entre los intereses del grande y pequeño comercio; y cuarto, por la precisa conexión con el urbanismo (Miguez MACHO: «El reparto de competencias en materia de comercio interior en la Ley de Ordenación del Comercio Minorista», RArAP, n. 11 , diciembre de 1997, p. 94).
} 


\section{A. Alternativas a la licencia comercial}

Hemos aludido a la idea de novedad por cuanto la autorización que la Ley exige se inserta con carácter novedoso en nuestro ordenamiento, donde no existía previsión alguna anterior al respecto ${ }^{2}$. El legislador disponía de tres vías a través de las cuales podía facultar a la Administración al objeto de que interviniese y controlase la instalación de los hoy denominados por la LOCM «grandes establecimientos». La primera, efectuar una regulación o una adaptación de los instrumentos de ordenación urbanística existentes en cada Comunidad Autónoma, de modo que dieran entrada y cabida a mayores y más puntuales criterios autonómicos sobre el «urbanismo comercial» (extrañamente, aun constituyendo, a nuestro entender, la solución más idónea, nadie optó por ella) o, en su caso, alternativamente, aprobar la correspondiente normativa administrativa y, dentro de ella y característicamente, los Planes Generales de Equipamientos Comerciales (u otros de parecida o similar denominación), ya disponibles por varias Comunidades Autónomas y cuyo contenido debieran observar inexcusablemente los Ayuntamientos al momento de tramitar la licencia de apertura (es el supuesto contemplado en el art. 14.2 de la Ley aragonesa 9/1989, de ordenación de la actividad comercial, en el art. 13 de la Ley vasca 7/1994, reguladora de la actividad comercial, y en el art. 17 de la Ley Canaria 4/1994, con la misma denominación que la anterior -las tres Comunidades contemplaron transitoriamente la exigencia de un informe o, también, de una autorización autonómica, hasta tanto se aprobase la correspondiente normativa que había de ser aplicada por las entidades locales). Una segunda vía de actuación del legislador estatal podía haberla constituido la ya tradicional en nuestra legislación técnica del informe (normalmente vinculante) a emitir por parte de la Comunidad Autónoma en determinados trámites administrativos y particularmente en el de otorgamiento de la licencia de apertura que debiera ser concedida por parte del Ayuntamiento (es el caso que se preveía en el art. 24 de la Ley andaluza 1/1996, de comercio interior, y en el art. 10 de la primitiva Ley catalana 3/1987, de equipamientos comerciales — no refundida en el Decreto legislativo $1 / 1993-)^{3}$. Por fin, la tercera vía de actuación, y de la

\footnotetext{
2 El antecedente lo ha constituido, tal como indican Cases Pallarés y Pons Cánovas: (La implantación de grandes establecimientos comerciales, Madrid, 1998, pp. 25-27), la Ley francesa de 17 de diciembre de 1973, conocida como Ley Royer, recientemente modificada por la Ley de 5 de julio de 1996 incrementando la tutela y control de los poderes públicos.

${ }^{3} \mathrm{El}$ informe vinculante de una Administración en el trámite efectuado por otra sigue siendo algo tradicional en nuestro Derecho. De ello se hicieron eco las legislaciones autonómicas recogiendo la mecánica diseñada por diversos preceptos de las normas estatales. A título de ejemplo, artículo 15.3 de la Ley andaluza 2/1989 (informe de la Agencia andaluza medio ambiental en el expediente de modificación del suelo no urbanizable afectante a Parques Naturales), artículo 10 de la Ley andalu-
} 
cual ha hecho uso el legislador estatal, consiste en introducir una nueva autorización administrativa que se sume o añada a otras exigidas por el ordenamiento para poder llevar a cabo la apertura de determinados establecimientos (era el evento diseñado por el art. 7 de la Ley gallega 10/1988, de ordenación del comercio interior, y por el art. 17 de la Ley valenciana $8 / 1986$, de ordenación del comercio y superficies comerciales —de ahí que hayamos aludido a una novedad «relativa»-, y es el caso previsto en el art. 11 de la Ley $2 / 1996$, de 18 de junio, de Castilla y León sobre Equipamientos Comerciales, aprobada ya bajo la vigencia de la LOCM y adaptada a ésta ${ }^{4}$, como también habrán de ajustarse las leyes autonómicas precitadas - algunas ya lo han hecho- y como también se adaptaron, al haberse dictado con ulterioridad a ella, la Orden de la Consejería de Agricultura y Comercio de la Junta de Extremadura, de 1 de agosto de 1996, el Decreto 56/1996, de 19 de agosto, del Principado de Asturias, el Decreto 121/1996, de 29 de noviembre, de la Comunidad de Cantabria, el Decreto 217/1996, de 12 de diciembre, del Gobierno balear, el Decreto 20/1997, de 26 de marzo, del Gobierno riojano y, de manera más reciente y con una regulación más detallada y completa que otras, la Ley catalana 1/1997, de 24 de marzo, desarrollada por el Decreto 244/1997, de 16 de septiembre).

Esta última solución escogida no creemos que sea ni más ni menos garante de los derechos de los ciudadanos que las anteriormente citadas, ni que se ajuste en mayor o menor grado al conjunto y contenido del ordenamiento jurídico. No obstante, es la que se contenía en el proyecto inicialmente presentado por el Grupo Convergència i Unió $\left(B O C G-C D \mathrm{n}^{\circ}\right.$ $10-1$, de 26 de julio de 1993, art. 39) y la que finalmente y tras numerosas vicisitudes ha podido obtener la consagración normativa ${ }^{5}$. A nosotros nos parece la menos idónea de las posibilidades existentes, pues sin per-

za 8/1988 (informe de la Administración del Estado en la ocupación del dominio público marítimo terrestre), artículo 17 de la Ley gallega 11/1985 (informe de la Administración del Estado en la tramitación de instrumentos de planeamiento en los municipios costeros), artículo 30.2 de la Ley canaria 7/1990 (informe del Consejero Territorial en los expedientes municipales para restauración de la realidad fisica alterada), artículo 6.3 de la Ley catalana 12/1981 (informe autonómico en los proyectos de explotación de actividades extractivas), etc.

${ }^{4}$ De manera curiosa, la Ley castellano-leonesa se dictó careciéndose en el Estatuto de competencia exclusiva en materia de comercio interior, intentando amparar sus contenidos tan sólo en el título competencial concerniente a la ordenación territorial y el urbanismo.

5 No obstante lo dicho, recordemos también que el libro sobre los comentarios a la LOCM publicado por la Editorial Praxis y coordinado por ARIMANY y Manubens (Barcelona, 1996), explica en su presentación (pp. IX-XI) que la tramitación de dicha Ley estuvo marcada por el clima de confrontación entre las grandes superficies y el denominado comercio tradicional. Confrontación que, se dice, fue resuelta a favor de este último, siendo signo de ello la actual existencia de la denominada «licencia comercial». 
juicio de la regla general hoy asentada en nuestro ordenamiento sobre el carácter positivo del silencio administrativo y de la utilidad que pudiera comportar desde el punto de vista del eventual incremento del control por parte de los poderes públicos, para el ciudadano no es otra cosa que un impedimento más a superar en la carrera de obstáculos (no todos fáciles de salvar) que ha de celebrarse con el fin de obtener las diversas autorizaciones administrativas exigibles para la instalación y el ejercicio de una actividad, lo que cuesta encajar o sintonizar con la servidumbre objetiva de los intereses generales que la Constitución impone a las Administraciones públicas y que podría llevarse igualmente a cabo insertando el control autonómico a través de una planificación previamente diseñada ${ }^{6}$ $\mathrm{o}$, en su caso, conjugándolo con otras intervenciones autonómicas que se hacen igualmente precisas en la instalación del establecimiento, puntualmente, la de las Comisiones competentes en materia de precios o en materia de urbanismo y medio ambiente, sea en el trámite de aprobación de un instrumento de planeamiento, sea en el de emisión de informe en el procedimiento concerniente a la obtención de licencia de apertura ${ }^{7}$.

\section{B. Establecimientos que precisan «licencia comercial»}

Según la Ley y como ya se ha reseñado, lo son los denominados «grandes establecimientos», cuyo concepto se consigna en el artículo 2.3 de la misma LOCM (también legislación básica). Recordemos que el concepto se remite a lo que cada Comunidad Autónoma decida configurar como tal, que es (y puede ser) ciertamente diverso. Sin perjuicio de ello, el legislador estatal ha decidido asentar un común denominador (desde 2.500 $\mathrm{m}^{2}$ de superficie útil para exposición y venta) que necesariamente debe observarse como punto de referencia para determinar el baremo superficial a partir del cual en todo caso se aplicará el régimen jurídico de los grandes establecimientos, lo que, como también se ha advertido, halla un

\footnotetext{
${ }^{6}$ A nuestro entender, la «licencia comercial» no debiera vincularse tan sólo, como parece inferirse de la letra de la Ley, al análisis de la situación comercial de la zona y sus expectativas de futuro, sino integrarse en las políticas económicas regionales planificadas y programadas a través de los instrumentos de ordenación del territorio, con una visión más amplia de las necesidades y las expectativas de la ciudad y de la región que la mera simplicidad del acotamiento de la licencia en función del comercio existente en la zona. En la comprensión de ToRnos MAS («Comercio interior y exterions, en la obra colectiva Derecho administrativo económico, dirigida por S. MARTiN-RETORTILLo, Madrid 1991, p. 600), el Plan no ha de permitir sólo el ordenar la actividad comercial, sino también dirigirla, pues el objetivo del Plan es la transformación de la realidad.

7 A pesar de que hoy sea generalmente admitida la licencia comercial, el propio Tribunal de Defensa de la Competencia (La competencia en España. Balance y nuevas propuestas. Madrid 1995, p. 104) entendió, como nosotros, que el control de la implantación comercial podia articularse a través de la intervención en la licencia de apertura de establecimientos.
} 
normal encaje en la acepción de nuestro Tribunal Constitucional reconociendo la competencia del Estado para señalar unos criterios unitarios mínimos en la materia ${ }^{8}$.

\section{C. ¿Precisa «licencia comercial» la ampliación y la modificación de grandes establecimientos?}

Consignemos por último, en relación a este tema, que la Ley estatal se refiere a la apertura de grandes establecimientos, silenciando lo concerniente a su ampliación y a su modificación, a diferencia de la alusión efectuada por la legislación de algunas Comunidades Autónomas. La cuestión, sin perjuicio de que habrá de ser objeto de una futura interpretación jurisprudencial, nos faculta a nosotros a ponerla sobre el tapete significando que admite la dualidad interpretativa en las Comunidades donde la norma jurídica aprobada no establezca nada al respecto. Si bien, frente a la eventual interpretación literal derivada del texto de la Ley estatal, a nuestro modo de ver, resulta razonable entender sometida a la autorización autonómica tanto la ampliación como la modificación del gran establecimiento, sino con carácter automático, sí al menos en cuanto pueda revestir un mínimo grado de sustancialidad ${ }^{9}$. Y ello creemos debe ser así, primero y con carácter general, en tanto que la «licencia comercial» no es una autorización de las que se agotan con una concreta operación,

${ }^{8}$ Cada Comunidad Autónoma, podrá, pues, rebajar (que no incrementar) el baremo superficial en el modo y manera que más se ajuste a sus necesidades, expectativas e intereses (también en este sentido, PIÑAR MAÑAs, en la obra colectiva coordinada junto con BELTRÁN SÁNCHEZ: Comentarios a la Ley de Ordenación del Comercio Minorista y la Ley Orgánica complementaria, Madrid, 1997, p. 68 - recuerda la Ley canaria, que señala las superficies en función de la población de hecho de los municipios, $750 \mathrm{~m}^{2}$ para menos de 20.000 habitantes, $1.000 \mathrm{~m}^{2}$ para municipios de $20.000 \mathrm{a}$ 200.000 habitantes, y $1.500 \mathrm{~m}^{2}$ para los que superen los 200.000 habitantes-), a la vez que, dentro de una ordenación racional y no arbitraria, podrá señalar cualesquiera otros baremos conducentes a someter la instalación de una actividad comercial a los requisitos y régimen jurídico aprobados para los grandes establecimientos. La experiencia francesa, según CASES y PONS (ob. cit., p. 27), es la de incrementar el control (la Ley de 5 de julio de 1996 estableció la intervención administrativa especial en materia de comercio a partir de los 300 metros cuadrados de superficie, modificando la Ley anterior que la establecía en los 1.500 metros cuadrados. Advierten, no obstante (p. 116), que la pobreza del criterio superficial para la exposición y venta puede llevar a fraudes en la evitación de la licencia, simplemente separando las actividades comerciales en superficies anexas. De ahí que sea prudente añadir diferenciados baremos.

9 En contra, Ortega Álvarez, en la obra coordinada por Rodrigo Bercovitz Rodriguez-Cano y Jesús Leguina VILla: Comentarios a las leyes de ordenación del comercio minorista, Madrid, 1997, p. 66, en el entendimiento de que tan sólo las Comunidades Autónomas que han recogido en su Estatuto la competencia en materia de comercio interior pueden efectuar una regulación de tal índole. De ahí que crea criticable la Orden de la Consejería de Economía y Empleo de la Comunidad de Madrid, $n$. $^{\circ} 3.323 / 1996$, de 16 de abril, en la que se efectúa la regulación cuando la competencia estatutaria (art. 28) tan sólo alcanza a la ejecución de la legislación del Estado. 
sino de aquellas otras que prolongan su vigencia en el tiempo, como lo es también la licencia de apertura regulada en el Reglamento de Actividades Molestas - RAMINP-, y las licencias concedidas al amparo del mencionado Reglamento han sido configuradas por nuestra jurisprudencia como autorizaciones de funcionamiento, es decir, que al momento de obtener la licencia, no se adquiere por el administrado un derecho subjetivo pleno que le faculte al ejercicio de la actividad en las condiciones inmóviles en las que obtuvo la autorización, sino que tan sólo se adquiere un derecho debilitado o se mantiene una simple expectativa de derecho que sustenta y ampara un vínculo permanente entre Administración y ciudadano encaminado a la protección y aseguramiento constante del interés público, de modo y manera que la Administración podrá alterar las condiciones futuras para el ejercicio de la actividad y establecer medidas de corrección y adaptación, disciplinando, subordinando y condicionando el interés particular a las variantes y prevalentes exigencias del interés público, hasta, si fuere preciso, imponer el cierre del establecimiento (SSTS de 4 de octubre de 1986 - RA 7.402-, 25 de mayo y 28 de septiembre de 1987 -RA 5.845 y 8.262 - 1 y 19 de febrero y 11 de octubre de 1988 -RA 669, 1.371 y 7.475 - y 23 de marzo y 10 de junio de 1992 - RA 3.229 y 5.109 - etc.). Y segundo, y derivado de lo anterior, en tanto que para el otorgamiento de la «licencia comercial» la Ley contempla la evaluación de unos parámetros que no son estáticos en el tiempo, sino que dependen del modo en que la iniciativa privada y la concepción de la tutela del interés público los haga evolucionar, de modo y manera que al momento de pretenderse la ampliación o la modificación de un gran establecimiento, resultará prudente - si no procedente- el reevaluar o volver a ponderar los parámetros inicialmente utilizados, tanto a la luz de un diferenciado marco fáctico como en función de las expectativas previsibles y la intencionalidad que guía la ampliación o modificación pretendida ${ }^{10}$.

\footnotetext{
${ }^{10}$ La STS de 23 de noviembre de 1994 (RA 10.352) declaró acomodado a Derecho el requisito impuesto por la Administración de la Comunidad Autónoma andaluza de que los establecimientos en los que se llevase a cabo la explotación de máquinas recreativas renovasen su autorización administrativa cada cinco años. Ello, a nuestro entender, marca el inicio, la pauta y la tendencia normativa de considerar las autorizaciones de actividad como autorizaciones de funcionamiento, con necesidad de adaptación constante a los requisitos de interés público prevenidos por el ordenamiento jurídico en cada momento y lugar. Tampoco se olvide, desde el punto de vista exclusivamente urbanístico, que el artículo 178.1 del Texto Refundido de la Ley del Suelo de 1976 - al igual que hacía el art. 242.2 del Texto de 1992- y el artículo 1, apartados 10 y 13 del Reglamento de Disciplina Urbanística, sujetan a licencia municipal el mero cambio de uso del inicialmente autorizado.
} 


\section{LA COMPETENCIA DE LAS COMUNDADES AUTÓNOMAS}

Aun cuando dicha competencia se proclama de manera indubitada por el artículo 7 LOCM, también se consigna de manera extraña y reiteradamente en el artículo 6.1 (ambos, legislación básica), por si alguien pudiese ostentar duda alguna o temor en función de las actuales líneas que sobre la distribución del poder había venido señalando hasta la fecha el Tribunal Constitucional interpretando nuestra Carta Magna ${ }^{11}$.

El proyecto inicialmente presentado ante el Parlamento aludía (art. 39.1) al otorgamiento por el Estado o por las Comunidades Autónomas en función de la asunción de competencias. Pero cuando el proyecto fue aprobado por la Comisión legislativa de Economía, Comercio y Hacienda (BOCG-CD n. ${ }^{\circ} 10-17$, de 26 de septiembre de 1995), los artículos 6 y 7 del nuevo texto ya recibieron un contenido igual al ahora referenciado, y así fue aprobado por el Congreso (BOCG-CD n. $.^{\circ} 10-19$, de 30 de diciembre de 1995) y por el Senado (BOCG-S n. ${ }^{\circ} 27-\mathrm{g}$, de 27 de noviembre de 1995) rechazando las diversas enmiendas que buscaban alterarlo (publicadas en el BOCG-S n. ${ }^{\circ} 27$-e, de 23 de octubre de 1995). La redacción actualmente vigente es reflejo de las enmiendas números 153 y 154 presentadas por el Grupo Socialista en el Congreso, prácticamente coincidentes con las números 413 y 414 presentadas por el Grupo Parlamentario Catalán (BOCG-CD n. ${ }^{\circ} 10-14$, de 11 de octubre de 1994). No obstante, lo que aquí y ahora nos interesa a nosotros reseñar es que en la multiplicidad y variedad de enmiendas presentadas en la tramitación de la Ley, nunca llegó a cuestionarse la competencia de las Comunidades Autónomas para informar o para autorizar la apertura de los grandes establecimientos fiscalizando determinados aspectos comerciales. Únicamente se separó de tal criterio, y de manera relativa, el Grupo Popular en la enmienda $n .^{\circ} 227$ a la totalidad del texto y en la parcial $n .^{\circ} 276$ (BOCG-CD n. ${ }^{\circ} 10-14$, de 11 de octubre de 1994) que preveían (arts. 11 y 39 , respectivamente) la autorización municipal previo informe del Ministerio de Comercio y Turismo y haciendo salvedad de la competencia de las Comunidades Autónomas ${ }^{12}$.

\footnotetext{
"La repetición del contenido legal, que pone de relieve el evidente tinte autonomista en su concepción, creemos que obedeció al acuerdo de modificación existente entre los grupos parlamentarios socialista y catalán, según se infiere de lo que más adelante se reseña, al presentarse enmiendas por ambos grupos con casi identidad de contenido material y redaccional.

12 Ortega Álvarez (ob. cit., p. 71) cuestiona la constitucionalidad de la medida de asignación competencial a las Comunidades Autónomas en cuanto que implica una injustificada limitación de la competencia autonómica en materia de comercio interior y autoorganización.
} 
Para el legislador, pues, estaba claro a quien correspondía la competencia para otorgar la novedosa licencia comercial. La razón de ello, a nuestro entender, no podía ser otra que el haber sido ya resuelta la cuestión por parte del Tribunal Constitucional, tímidamente en las SSTC 37/1981 y 71/1982 y con más precisión en la STC 88/1986 (FJ 6), al advertir, a nuestro juicio con evidente tino, que la unidad de mercado proclamada y derivada de nuestro texto constitucional no significa uniformidad, ya que la existencia de las Comunidades Autónomas comporta una diversidad de regímenes jurídicos y, por tanto, de intervenciones de los poderes públicos. La compatibilidad entre la unidad de economía de la Nación y la diversidad jurídica que deriva de la autonomía ha de buscarse a través de la idea de equilibrio, de modo que la actividad de la Comunidad Autónoma se lleve a cabo dentro del ámbito de su competencia y que resulte proporcionada al objeto legítimo que persigue, de manera que las diferencias y peculiaridades en ella previstas resulten adecuadas y justificadas por su fin ${ }^{13}$.

De manera directa, fueron las sentencias dictadas sobre las Leyes reguladoras del comercio en diversas Comunidades Autónomas las que provocaron un reconocimiento expreso de la competencia autonómica para intervenir, sea mediante reglamentación, informe o autorización, la instalación de los hoy denominados grandes establecimientos, al reconocer en la STC 225/1993 (FJ 2, recordando las SSTC 111/1983 y 77/1984), que «sobre un mismo ámbito jurídico caben distintas competencias de órganos diferentes, y la atribución de unas competencias sobre un ámbito físico determinado no impide necesariamente que se ejerzan otras competencias en ese espacio», añadiendo, en el FJ 5.C, que «no es dudoso que el legislador autonómico se halle facultado para establecer requisitos de índole puramente administrativa para el ejercicio de la actividad comercial,... si bien habrá de ponderarse en cada caso si el número y la entidad de las exigencias administrativas introducidas por la legislación autonómica resultan proporcionadas al objeto legítimo que se persigue $y$, por tanto, adecuadas a su finalidad y, de otra parte, que tales requisitos no afecten a la igualdad básica de todos los españoles en el ejercicio de la actividad mercantil». Más tarde, las SSTC 227/1993, 228/1993 y 264/1993 vinieron a ratificar la misma doctrina, consignándose en la última de las citadas (FJ 6) que, sin perjuicio de la concesión de las licencias de apertu-

${ }^{13}$ Obviamente el Estado no queda desapoderado de intervención alguna. Además de lo que luego diremos sobre el Tribunal de Defensa de la Competencia, debe ponderarse que por Orden de 14 de febrero de 1996 (BOE 42/1996), modificada por otra de 22 de octubre de 1996, se creó el legalmente denominado «Observatorio de Distribución Comercial» como órgano de información, consulta y asesoramiento en materia de distribución comercial. 
ra de los grandes establecimientos comerciales por parte de los Ayuntamientos, la existencia de una autorización autonómica obedece al carácter supramunicipal de los intereses concernidos por la instalación de un centro de esta especie, justificándose por tanto la legalidad y la constitucionalidad de la medida autonómica interviniendo en materia de comercio la apertura de los grandes establecimientos ${ }^{14}$.

\begin{abstract}
14 Aunque el tema de la competencia de las Comunidades Autónomas en esta materia excede, con mucho, al objetivo de este comentario, recordemos aquí de nuevo, por su vínculo con el tema de la apertura de los grandes establecimientos, que la solución al tema de la competencia vendrá ofertada fundamentalmente por los elementos básicos o características esenciales de la situación de hecho que pretendan solucionarse o afectarse con la proposición normativa, al margen de que existan muchos otros también afectados pero que no revistan tal carácter de esencialidad, es decir, analizando la finalidad fundamental o prevalente de la norma, con independencia de que pueda ostentar otras accesorias. En este contexto se desenvuelven los diversos contenidos de la jurisprudencia de nuestro Tribunal Constitucional en cuanto que establecen que «la defensa de la competencia, en un aspecto normativo, comprende toda legislación ordenada a la defensa de la libertad de la competencia mediante la prevención y, en su caso, mediante la represión, de las situaciones que constituyan obstáculos creados por decisiones empresariales para el desarrollo de la competencia en el mercado»" (STC 71/1982). «Ś́lo a través de sus órganos centrales puede el Estado determinar cuál es el ámbito propio de la actividad libre del empresario mercantil, y sólo la legislación emanada de tales órganos centrales puede regular la forma en la que nacen y se extinguen los derechos y obligaciones a que el ejercicio de dicha actividad puede dar lugar» (STC 88/1986). «La defensa del consumidor es un concepto de tal amplitud y de contornos tan imprecisos que, con ser dificultosa en ocasiones la operación calificadora de una norma cuyo designio pudiera entenderse que es la protección del consumidor, la operación no resolvería el problema, pues la norma pudiera estar comprendida en más de una de las reglas definidoras de competencias, lo que significa, en otras palabras, que esta materia se caracteriza por su contenido pluridisciplinar, en el que se concita una amplia variedad de materias que sí han sido directa y expresamente tomadas en consideración por el artículo 149. I CE a los efectos de concretar las competencias del Estado» (STC 15/1989). «Los poderes de control y vigilancia que competen al Estado para garantizar la ejecución del Derecho comunitario al amparo de lo prevenido en el artículo $93 \mathrm{CE}$, sin perjuicio de que le obliguen a dictar los instrumentos que le compele el ejercicio de esta función garantista, no pueden afectar a la competencia de las Comunidades Autónomas constitucionalmente garantizada» (STC 80/1993). «La necesidad de asegurar la acción conjunta, la información recíproca y la maximización de la eficacia, no crea por sí misma competencia alguna para el Estado ni puede ser utilizada por éste para limitar indebidamente las competencias autonómicas» (STC 80/1985). De manera más extensa, en la STC 225/1993 se explicitó: «En correspondencia con el presupuesto de un único orden económico nacional y la consiguiente existencia de un mercado nacional único (SSTC 1/1982, 32/1983, 11/1984, 24/1986 y $88 / 1986$, entre otras), esta competencia estatal (la ordenación de la actividad económica general) se extiende a un conjunto muy amplio de materias, justificándose la intervención del Estado siempre que para la necesaria coherencia de la politica económica general sea preciso adoptar decisiones unitarias (STC 29/1986). Pues, como también se ha dicho en la STC 186/1988, la competencia estatal sobre la ordenación de la economía responde al principio de unidad económica y abarca la definición de las líneas de actuación tendentes a alcanzar los objetivos de política global o sectorial fijados por la propia Constitución, así como la adopción de medidas precisas para garantizar la realización de los mismos. Por consiguiente, aun existiendo una competencia sobre un subsector económico que una Comunidad Autónoma ha asumido como «exclusiva» en su Estatuto, como es el caso del "comercio interion", esta atribución competencial no excluye la competencia estatal para establecer las bases y la coordinación de ese subsector, y que el ejercicio autonómico de dicha competencia pueda estar condicionado por medidas estatales que en ejercicio de una competencia propia y diferenciada puedan desplegarse autónomamente sobre diversos campos o materias, siempre que el fin perseguido responda efectivamente a un objetivo de planificación económica (STC
\end{abstract}




\title{
3. LA LEGALIDAD DE LA «LICENCIA COMERCIAL»
}

Quizá pudiera pensarse (así lo hicieron diversos de los diputados que acudieron al Tribunal Constitucional) que la imposición de una «licencia comercial» para la apertura de los grandes establecimientos entraña una vulneración del principio de libertad de empresa reconocido en nuestra Constitución, en línea con el mismo reconocimiento operado en el Acta Única Europea de 17 de febrero de 1986.

Lejos de ello, nuestra jurisprudencia comunitaria admitió con normalidad que los Estados pudieran efectuar una regulación separada de la propiedad y de otros derechos reales sobre los inmuebles, y de la actividad y las actuaciones que pudieran realizarse en los mismos ${ }^{15}$. Y en nuestro país, la Ley 16/1989, de Defensa de la Competencia - LDC - (arts. 1 y 2) y los RRDD 157/1992 y 1080/1992, prevén su eventual inaplicación

\begin{abstract}
75/1989). Ni tampoco excluye que el Estado intervenga cuando para conseguir objetivos de política económica nacional se precise una actuación unitaria de conjunto de la Administración del Estado, aun si se trata de una planificación de detalle (STC 29/1986) o de acciones o medidas singulares para alcanzar los fines propuestos en la ordenación de un sector económico (SSTC 95/1986 y y $152 / 1988$, entre otras). Dado el carácter general y abierto de las cláusulas que habilitan al Estado, con el posible riesgo de que por este cauce se produzca un vaciamiento de las concretas competencias autonómicas en materia económica, es obligado enjuiciar en cada caso la medida estatal de manera individualizada, examinando su finalidad de acuerdo con su objetivo predominante (STC 13/1989)». Y en la STC número 227/1993 se añadió: «El artículo 149.1.1 de la Constitución no puede erigirse en un obstáculo infranqueable a la existencia de las potestades normativas de las Comunidades Autónomas (asi se reconoció en las SSTC 102/1985 y 37/1987) especialmente cuando, como en el presente caso, los recurrentes no han aducido vulneración alguna de una regulación estatal concreta frente a las condiciones básicas que garanticen la igualdad de ejercicio de los derechos de los españoles en la materia. En suma, el precepto constitucional precitado no exige siempre un tratamiento jurídico uniforme de los derechos y obligaciones de los ciudadanos (STC 52/1988), pues tal exigencia haria imposible la existencia de un Estado descentralizado, aunque sí pueda ocurrir excepcionalmente cuando exista una justificación suficiente para ello. Por fin, las SSTC $228 / 1993$ y $264 / 1993$ resumen e invocan la mayor parte de las anteriores, concluyendo que resulta posible que existan normas sobre la protección de la libre competencia que funcionen también como garantía de los consumidores y que medidas adoptadas para la protección de éstos no dejen de tener incidencia en el desarrollo de la libre competencia, siendo necesario para determinar la diferenciada intervención de los poderes públicos el acudir a criterios teleológicos, precisando el objetivo predominante de la norma.
\end{abstract}

15 En la Sentencia Markx del TEDH, de 13 de junio de 1979, en relación al artículo 64 del Convenio para la Protección de los Derechos Humanos y de las Libertades Fundamentales, se distingue entre la posible diferente regulación que puedan efectuar los Estados sobre los «bienes», la "propiedad» y el «uso de los bienes», y en la Sentencia Sporrong y Lönnroth, del mismo Tribunal Europeo, de 22 de septiembre de 1982, se reconoce a los Estados el poder de reglamentar el uso de los bienes conforme a las exigencias del interés general. De manera más concreta, la Sentencia de 8 de diciembre de 1987 (es la que cuestionó la antecitada Ley francesa de 17 de diciembre de 1973 de orientación del comercio y la artesania -asunto 12/1987-) reconoce el acomodo al ordenamiento comunitario de la existencia de una autorización previa a la apertura de establecimientos de determinada superficie. 
en los supuiestos previstos por las leyes y los reglamentos que las desarrollen, como son las diferenciadas normas administrativas que imponen límites y requisitos para ejercer actividades e instalar establecimientos (en particular, las cada vez más numerosas y complejas, estatales, autonómicas y locales, atinentes a solventar cuestiones sectoriales y, en particular, a la ordenación del suelo y la protección del medio ambiente tanto urbano como de otra índole), siendo así reconocido por nuestro Tribunal Constitucional, sea en previsión de la subordinación de la libertad de empresa otros derechos también constitucionalmente protegidos, como pudiera ser la obtención de un medio ambiente adecuado (art. 45.2 CE, SSTC 64/1982, 227/1988, 170/1989 y 66/1991), sea, con normalidad, en el entendimiento de que los derechos constitucionales no están exentos de límites y requisitos en su ejercicio. Este último entendimiento, predicado con mayor frecuencia en relación a otras garantías fundamentales de los ciudadanos, es el que poco a poco se ha ido reconociendo por el Tribunal Constitucional con mayor amplitud en el ámbito en el que nos hallamos. Así, se comenzó declarando que en un Estado de Derecho es lícitamente posible para el legislador la introducción de límites y restricciones al ejercicio de derechos de contenido patrimonial, por razones derivadas de su función social (STC 111/1983), se siguió consignando, a partir de la Sentencia 37/1987 (FJ 5), que el ejercicio del derecho a la libertad de empresa ha de quedar condicionado por las restricciones que se establezcan en cuanto a la libertad de explotación y por los deberes positivos que en relación a la misma se impongan por la Administración, y se ha venido a concluir de momento y de manera tajante en las SSTC 225/1993 y 227/1993 (FJ 4) y en las que con ellas concuerdan, que «en un Estado social y democrático de Derecho como el que proclama el artículo 1 de la Constitución es lícitamente posible para el legislador la introducción de límites y restricciones al ejercicio de derechos de contenido patrimonial, como son los de propiedad y libertad de empresa, por razones derivadas de su función social (STC 111/1983). En este sentido, la libertad de empresa, junto a su dimensión subjetiva, tiene otra objetiva e institucional, en cuanto elemento de un determinado sistema económico, y se ejerce dentro de un marco general configurado por las reglas, tanto estatales como autonómicas, que ordenan la economía de mercado y, entre ellas, las que tutelan los derechos de los consumidores, preservan el medio ambiente u organizan el urbanismo y una adecuada utilización del territorio por todos. En definitiva, la libertad de empresa no ampara entre sus contenidos - ni en nuestro ordenamiento ni en otros semejantes - un derecho incondicionado a la libre instalación de cualesquiera establecimientos comerciales en cualquier espacio y sin sometimiento alguno a requisitos o condiciones, haciendo caso omiso de las diferentes normativas —estatales, autonómi- 
cas o locales- que disciplinan múltiples aspectos de relevancia económica, como, entre otros, el comercio interior y la ordenación del territorio».

\section{LA FUNDAMENTACIÓN Y EL TRÁMITE DE LA «LICENCIA COMERCIAL»}

Tradicionalmente, en el ámbito del Derecho administrativo se viene predicando con generalidad el carácter reglado de las autorizaciones administrativas (sin perjuicio de que muy pocas se sujeten a igual trámite, regulación y efectos), es decir, que deben ser concedidas o denegadas mediante un acto de constatación, comprobando si el solicitante reúne o no los requisitos prevenidos por el ordenamiento para su obtención. De ello se ha hecho eco con cierta frecuencia nuestra jurisprudencia (SSTS de 8 de octubre de 1954 - RA 2.391 —, 2 de marzo de 1963 - RA 1.384, 11 de mayo de 1964 - RA 3.573 - 15 de marzo de 1967 - RA 1.707 -, 11 de febrero de 1981 - RA 859-, 21 de diciembre de 1983 - RA 6.802 -, 4 de marzo de 1992 - RA 2.130 - 6 de octubre de 1992 - RA 7.764 - 14 de octubre de 1993 -RA 8.032—, 14 de junio de 1994 -RA 4628, la única, que nosotros conozcamos, afectante a un gran establecimiento-, 27 de junio de 1994 -RA 4.999—, 27 de diciembre de 1994 -RA 10.271—, etc.). Existen, no obstante, algunos ámbitos donde el legislador, directa o indirectamente, ha admitido un cierto margen de discrecionalidad (casinos, salas de juego, máquinas recreativas, instalaciones en suelo no urbanizable, importación de estupefacientes, permisos de armas, etc.), que con evidencia son los menos frente a la regla general asentada en el marco de nuestro ordenamiento, a la par que ha existido algún supuesto donde con naturalidad estaba previsto el carácter reglado de la autorización y, sin embargo, la evidente concurrencia de razones de interés público aconsejaba denegarla (SSTS de 4 de julio de 1962 - RA $2.854-, 10$ de febrero de 1970 - RA $830-, 20$ de junio de $1980-\mathrm{RA}$ 3.323 -, etc.), bien entendido que el interés público justificativo de la decisión debiera estar anclado en reglas y principios del ordenamiento y ser patente, notorio y ostentar la suficiente relevancia para ello ${ }^{16}$.

\footnotetext{
16 A pesar de que la discrecionalidad es consustancial al normal actuar de las Administraciones públicas, no puede olvidarse, de una parte, que uno de los signos que marcan la evolución del Derecho administrativo lo es precisamente la imposición de límites cada vez más estrechos al ejercicio de facultades discrecionales y, de otra parte, que nuestra jurisprudencia se desenvuelve en una interpretación muy rigurosa de la discrecionalidad en materia de autorizaciones, asumiendo que el ejercicio de la facultad ha de estar fundado en hechos, datos o circunstancias que supongan una modificación específicamente significativa de los requisitos objetivos y subjetivos exigidos para el otorgamiento de las autorizaciones concedidas a otros sujetos (SSTS de 14 de noviembre de 1984 - RA 6.213-,
} 
La polémica intentó ser trasladada al Tribunal Constitucional precisamente en el ámbito donde nos hallamos, apuntando que la indeterminación de los criterios señalados por las leyes autonómicas para el otorgamiento de las «licencias comerciales» propiciaría grandes dosis de arbitrariedad, cuya interdicción viene garantizada por el artículo $9 \mathrm{CE}$. El Tribunal Constitucional no lo entendió así. En primer lugar, en la STC 225/1993, afectante a Ley valenciana de la ordenación del comercio, asumió (FJ 7) que la amplitud configurada por la Ley para conceder o denegar la apertura de los establecimientos comerciales no es óbice para determinar su ilegalidad o su inconstitucionalidad, pues habrá de esperarse al desarrollo reglamentario para calibrar la ilicitud de los criterios anunciados en la Ley. A ello añadió en la STC 227/1993 (Ley catalana de equipamientos comerciales) que no hay obstáculo alguno (FJ 4) a que la Ley —estatal o autonómica - habilite expresamente al Reglamento para concretar o desarrollar sus mandatos en un objeto concreto, fijando para ello sus criterios mediante una imprescindible colaboración entre potestades legislativa y reglamentaria que, en un asunto como éste, en el cual son previsibles numerosas ordenaciones sectoriales muy detalladas, resulta inevitable e incluso conveniente. Y sobre ello se erigió, por fin, la interpretación consignada en la STC 264/1993 (Ley aragonesa de ordenación comercial) en la que se asumió (FJ 6) que los criterios establecidos, con independencia de lo genéricos que pudieran ser - parcialmente coincidentes con los de la Ley catalana-, o de su carácter transitorio, no propician arbitrariedad de clase alguna, como tampoco la propicia el diseño de conceptos jurídicos indeterminados que hayan de integrar el canon de cualquier decisión administrativa. Cuestión distinta (expresaba la STC 225/1993) sería el que la Ley pudiera entrañar una verdadera deslegalización por ausencia de criterio alguno para ser utilizado en vía reglamentaria, lo que no acaecía en los supuestos examinados, donde la norma legal fijaba los parámetros, aunque fueran de carácter mínimo, a los que había de acomodarse la normación reglamentaria ${ }^{17}$.

21 de junio de 1984 -RA $5.684-17$ de enero y 8 de marzo de 1986 - RRA 55 y $1.772-, 25$ de mayo de 1990 y 25 de enero y 21 de abril de 1992 -RRA 1.342 y $4.103-$ ), debiendo ser la Administración la que explique, justifique el por qué una autorización ha de ser denegada, parangonando la denegación con otros supuestos de hecho similares en los que resultó discrecionalmente concedida.

17 ARIÑO ORTIZ, en Principios constitucionales de la libertad de empresa. Libertad de comercio e intervencionismo administrativo. Madrid, 1995, p. 67, lanzó una dura crítica sobre los criterios diseñados para la concesión de la licencia, entendiendo que su otorgamiento sería discrecional en función de los criterios del Gobierno de turno, o mínimamente condicionado por el abstracto Plan que cada Comunidad tenga aprobado. Por su parte y en similar sentido, Piñar Mañas (ob. cit., p. 69) expuso que la amplitud y la indeterminación de los criterios aprobados no se adecúan excesivamente al principio constitucional de seguridad jurídica. 
El Tribunal Constitucional, pues, entró a analizar cautelosamente el tema de las facultades discrecionales en el otorgamiento de la autorización, optando por no efectuar una alusión expresa al concepto. No obstante, en los términos y en los silencios utilizados, apuntó (aunque no de manera directa) que las leyes autonómicas (como hoy la LOCM) no contenían un reconocimiento expreso de facultades discrecionales, sino que - a lo sumo - reseñaban simples conceptos jurídicos indeterminados que debieran ser integrados en su día reglamentariamente (o, en ausencia de reglamento o, ante un defecto de concreción, por el órgano a quien ello competa). Por lo demás, también se ocupó de lo que constituía su principal misión, es decir, de aclarar que no podía inferirse apriorísticamente arbitrariedad de clase alguna de los escasos puntos de referencia consignados por las leyes de las Comunidades Autónomas, los cuales proporcionan criterios suficientes para amparar la creación de un reglamento e informar - directa o indirectamente- el actuar administrativo y, en su caso, permitir la efectividad de la tutela judicial ${ }^{18}$.

En nuestro caso particular, es la Ley estatal (art. 6.2) la que fija y diseña los dos parámetros (ciertamente mínimos, pero obviamente suficientes a tenor de la jurisprudencia constitucional previamente citada) que habrán de ser tenidos en cuenta para el otorgamiento o la denegación de la «licencia comercial». A nuestro entender, la LOCM no es excesivamente congruente al establecer los dos parámetros como legislación básica (6.2) renunciando a tal carácter básico y admitiendo la supletoriedad de la normativa al momento de definirlos o de expresar su contenido (6.3 y 6.4). Dicho de otro modo, se faculta a cada Comunidad Autónoma a que defina normativamente y de manera diversa el concepto inicialmente interpretado, asentado, acotado y definido por el legislador estatal. Ello, si bien no significa que pueda advertirse tacha de ilegalidad -al menos nosotros no la vemos - provoca, sin embargo y a nuestro modo de ver, una distonía que carece de justificación, pues si bien el legislador estatal podría haber renunciado perfectamente a establecer los parámetros aprobados, una vez habiéndolo efectuado, no tiene excesivo rigor científico el optar por definirlos o integrarlos con un contenido que puede ser interpretado de muy diversas maneras y alterado por parte de las Comunidades Autónomas.

\footnotetext{
${ }^{18}$ La realidad ha puesto de relieve la posibilidad de realizar el control judicial. CASES y Pons (ob. cit., p. 122) ponen el ejemplo de la Sentencia del TSJ de Cataluña de 27 de octubre de 1995, que anula, por no ser conforme a Derecho, un informe negativo para la implantación de un gran establecimiento emitido por el órgano competente de la Administración autonómica catalana. No ha de olvidarse, creemos, en este ámbito, que precisamente en lo que concierne a las autorizaciones económicas, la complejidad normativa se va incrementando progresivamente, superándose así el concepto de autorización como control negativo del ejercicio de derechos e intentando encauzar positivamente la actividad pretendida a través de unos objetivos previamente definidos.
} 
Ello, con independencia de que la legalidad, la conveniencia y la oportunidad aconsejen el que sean éstas las que, en función de sus necesidades y sus aspiraciones, deban establecer el paquete de requisitos y el más concreto marco circunstancial al que deban someterse los ciudadanos que deseen obtener la «licencia comercial» para la instalación de un gran establecimiento ${ }^{19}$.

\section{A. La comprobación de la adecuación de la instalación al equipamiento comercial previamente existente en la zona}

Los dos parámetros establecidos por la Ley son de una ambigüedad extrema, aunque, como hemos advertido, en el marco en el que se ubican no precisan de mayor concreción. En realidad, si se observan detenidamente los requisitos contemplados, la Ley tan sólo exige a las Comunidades Autónomas que tengan en cuenta la situación actual del comercio en la zona y sus expectativas de futuro, lo que parece de una lógica incuestionable.

El primero de los parámetros se traduce, pues, en tener en cuenta el equipamiento comercial previamente existente en la zona (por lo demás, a ello se alude también por casi todas las leyes autonómicas dictadas hasta esta fecha). Según la LOCM, existirá equipamiento comercial adecuado cuando garantice a la población existente y, en su caso a la prevista a medio plazo, una oferta de artículos en condiciones de calidad, variedad, servicios, precios y horarios conforme a la situación actual y con las tendencias de desarrollo y modernización del comercio al por menor.

El contenido legal, con independencia de no ser básico (puede, por tanto, ser sustituido por las Comunidades Autónomas que ostenten competencia en la materia), tampoco deja de ser relativo. Primero, porque son los establecimientos que desean instalarse (la iniciativa privada) los interesados con carácter prevalente en realizar (como así se ha hecho en los recientemente instalados) exhaustivos estudios sobre las necesidades y

\footnotetext{
19 Recuérdese, no obstante, que en el ámbito de las autorizaciones administrativas en el que nos hallamos incide la regulación introducida por la LRJAP [art. 35.g)], en cuanto que implantó el derecho de los ciudadanos «a obtener información y orientación acerca de los requisitos jurídicos o técnicos que las disposiciones vigentes impongan a los proyectos, actuaciones o solicitudes que se propongan realizar», lo que, aún carente de desarrollo reglamentario (salvo en lo que concierne a ciertos aspectos de la información regulados en el RD 208/1996, de 9 de febrero) y de interpretación jurisprudencial, supera con creces el limitado contenido del derogado (por la Ley 7/1997) artículo 33 de la Ley de Procedimiento Administrativo y abre una puerta de insospechado alcance en relación al asesoramiento que la Administración pueda y deba prestar al ciudadano, en nuestro caso, en relación a la obtención de una «licencia comercial».
} 
expectativas de los consumidores, buscando los criterios de mayor proporción e idoneidad en la ubicación, así como el pacto previo, la conformidad y el asentimiento con los poderes públicos y, segundo, porque desde el punto de vista de la valoración administrativa, es sumamente dificil entender adecuada una oferta de artículos cuando el constante avance de las comunicaciones relativiza cada vez más las distancias y cuando la incesante aparición de nuevos o diferenciados bienes en el mercado viene también a relativizar, modular y alterar las necesidades y los hábitos de consumo y compra. Ello, con independencia y al margen de las tendencias derivadas de la propia personalidad de los consumidores y de la concepción de los poderes públicos, que pudieran estar interesados en la potenciación de determinados sectores o en la generación de riqueza o de mayor tráfico de bienes en concretas parcelas del territorio.

En cualquier caso, insistimos, habrán de ser las Comunidades Autónomas las que definan de una manera puntual y las que establezcan, a través de la planificación, o por otras vías, los requisitos en orden a la valoración o a la consideración como «adecuado» del equipamiento comercial existente y que condiciona la instalación de futuros equipamientos, siempre que ello se efectúe con patrones que permitan una ulterior fiscalización por parte de los Tribunales del orden jurisdiccional contencioso administrativo en su comprobación de acomodo de la decisión administrativa adoptada a los principios y preceptos del ordenamiento jurídico (STC 227/1993, FJ 5, STC 264/1993, FJ 6).

\section{B. Los efectos de la instalación sobre la estructura comercial de la zona}

Es el segundo de los parámetros establecidos por la LOCM y que, según la citada norma, habrá de valorarse teniendo en cuenta la mejora que para la libre competencia suponga la apertura de un nuevo gran establecimiento en la zona, así como los efectos negativos que aquélla pudiera representar para el pequeño comercio existente con anterioridad.

Tal concepto (el impacto de futuro de la instalación y en particular en el pequeño comercio) ya se hallaba también previsto de manera genérica en la legislación de algunas Comunidades Autónomas (en realidad, tal consideración fue el primer estímulo que movió a la intervención administrativa a través de la nueva licencia), si bien ninguna había osado introducir la referencia a la protección de la libertad de competencia, toda vez que ello constituye una materia asignada al Estado. Parece que el legisla- 
dor estatal, a través de una norma de carácter supletorio pretendiese ahora que fueran las Comunidades Autónomas las que ponderen los efectos que pudiera presentar la instalación de un gran establecimiento sobre el principio de libertad de competencia, lo que no podría considerarse descabellado, pues dentro de los inconvenientes o de las trabas jurídicas que en algún raro o extraño supuesto pudieran justificar la denegación de una «licencia comercial», habrán de ubicarse necesariamente los atinentes al principio de libertad de competencia, claramente imbricado con los contenidos de la legislación autonómica comercial y con otros principios atinentes a la ordenación del territorio y a la consideración y regulación del denominado urbanismo comercial, lo que, como advertimos, podría ser controlado adecuadamente por la Administración de las Comunidades Autónomas. Sin embargo, ello no parece que sea así, pues con independencia de que - volvemos a insistir- la previsión de la «impactación sobre la estructura comercial de la zona» es una norma supletoria que podrá ser trastocada o alterada y, en cualquier caso, desarrollada y convenientemente puntualizada por la legislación de las Comunidades Autónomas, en realidad la protección de la defensa de la competencia no se ha querido remitir ni se asigna a las Comunidades Autónomas, dado que habrá de ser la Administración del Estado, a través del Tribunal de Defensa de la Competencia, la que haga efectivo control y uso de las competencias que constitucionalmente se le asignan y no se delegan formalmente. A ello aludimos seguidamente.

\section{El informe del Tribunal de Defensa de la Competencia}

Como elemento igualmente novedoso, la LOCM introduce la intervención del Tribunal de Defensa de la Competencia, con carácter preceptivo en el otorgamiento de cualquier «licencia comercial» (el precepto - art. 6.2- es legislación básica), lo que evidentemente no había previsto ninguna de las Comunidades Autónomas que habían efectuado regulaciones sobre la materia, a excepción de las que han dictado disposiciones con ulterioridad a la vigencia de la LOCM ${ }^{20}$.

El informe, siendo preceptivo, sigue, no obstante, la regla general asentada en el artículo 83.1 de la Ley 30/1992 — LRJAP - sobre la no

\footnotetext{
${ }^{20}$ La introducción del informe del Tribunal de Defensa de la Competencia obedeció a la previsión de la enmienda $n .^{\circ} 153$ presentada por el Grupo Socialista. La alusión a este informe era prácticamente lo único que la diferenciaba del redacción de la enmienda $n^{\circ} 413$ presentada por el Grupo Catalán, en la que no se hacia referencia alguna al mismo. CASES y Pons (ob. cit., p. 128) se extrañan de la exigencia del informe, dado que el comercial es el único sector - dicen-en el que la implantación de una actividad es analizada por el TDC.
} 
vinculatoriedad y así lo advierte expresamente la Ley 16/1989, de Defensa de la Competencia - LDC- ${ }^{21}$. Su emisión debiera operarse en el plazo de diez días, según previene el artículo 83.2 LRJAP, dado que ni la LDC, ni su reglamentación establecen otro plazo al respecto y, además, se remite (art. 50) a la supletoriedad del procedimiento administrativo general. Pasado dicho plazo, podrá entenderse emitido el informe con carácter favorable, sin perjuicio de que habrá de ponderarse que previsiblemente nos hallemos ante uno de los informes que el legislador considera «determinantes para la resolución del procedimiento» (83.3 LRJAP), lo que faculta - que no obliga- a interrumpirlo hasta que sea emitido.

El Tribunal de Defensa de la Competencia es, a pesar de su nombre, un órgano administrativo integrado en el seno de la organización del Estado y con sede en Madrid, aunque la actual norma reguladora se preocupe de advertir que ejerce sus funciones con plena independencia y sometimiento al ordenamiento jurídico (art. 11 LDC). Su función como órgano consultivo se halla prevista en el artículo 26.2 LDC, previniendo la emisión de informes a petición de las Comunidades Autónomas (o de determinados órganos, organizaciones, instituciones y Administraciones públicas), presumiblemente, a través de la Subdirección General de Informes creada por el RD 143/1993. Es también el órgano competente para la aplicación en España de los artículos 85.1 y 86 del Tratado de la Comunidad Europea y de su Derecho derivado, según previene el RD 295/1998, de 28 de febrero.

Si por un momento se olvidan o se marginan los criterios de oportunidad, economía, celeridad y eficacia en el procedimiento y en la actuación administrativas, nosotros entendemos que la intervención del referenciado Tribunal en el procedimiento de obtención de la «licencia comercial» resulta razonable y plenamente acomodada al ordenamiento jurídico, obviamente limitada al ámbito de defensa de la competencia (16 LDC) y aun cuando la Ley 3/1991, de competencia desleal, para nada aluda a la instalación de grandes establecimientos. No puede olvidarse en este contexto, como advierte la Exposición de Motivos de la LDC, que dicho Tribunal tiene encomendado el garantizar el orden económico constitucional en el sector de la economía de mercado desde la perspectiva de los intereses públicos. $\mathrm{Al}$ igual que tampoco cabe marginar, como ha puesto de relieve el Tribunal Constitucional, que la garantía de la uniformidad de

\footnotetext{
21 Es obvio, sin embargo, que aunque el informe no ostente carácter vinculante, una resolución administrativa que contravenga su contenido será con normalidad impugnada ulteriormente ante el orden contencioso administrativo (o incluso ante el Tribunal Constitucional -art. 76 LOTC-) con sustanciales y no pocas perspectivas de éxito en el resultado de la acción emprendida.
} 
las condiciones básicas en el ejercicio de derechos, la unidad de mercado y la afectación de intereses que excedan del ámbito autonómico son límites que deben tenerse presentes (STC 71/1982), como debe tomarse también en consideración que el artículo $38 \mathrm{CE}$ puede justificar las actuaciones de los poderes públicos encaminadas a la ordenación del mercado, mediante medidas dirigidas a evitar aquellas prácticas que puedan afectar o dañar seriamente un elemento tan decisivo en la economía de mercado como lo es la concurrencia de empresas, por lo que la protección de la competencia aparece así y se acentúa en su necesidad como concepción defensiva y no como una restricción de la libertad de empresa y de la economía de mercado que podrían verse amenazadas por el juego incontrolado de las tendencias naturales de éste (STC 88/1986), pues tanto el contenido de la libertad de empresa como los límites que pueden establecerse por las normas que regulen su ejercicio constituyen una cuestión que no está exenta de graves dificultades de definición a priori, con carácter abstracto y de general aplicación (STC 37/1987). La actividad empresarial, pues, por fundamentarse en una libertad constitucionalmente garantiza$\mathrm{da}$, ha de ejercerse en condiciones de igualdad, pero también, de otra parte, con plena sujeción a la normativa sobre la ordenación del mercado y de la actividad económica en general (STC 225/1993).

Si a ello sumamos las limitaciones del título "comercio interior» y la imprecisión de contornos del título «defensa del consumidor» y utilizable en este ámbito para justificar la autorización por parte de las Comunidades Autónomas y que ha sido puesto de relieve con insistencia por parte del Tribunal Constitucional a partir de la STC 71/1982 (según ya se ha expuesto más arriba), se convendrá que resulta ciertamente lógico que intervenga un órgano de la Administración del Estado al objeto de controlar la competencia ejercitable por ésta y sólo en la medida en que pudiera verse afectada (y sin perjuicio de que, en la eventualidad de poderse siempre opinar sobre la racionalidad de la idea o del proyecto, nada le impida el expresar su punto de vista de vista sobre la instalación pretendida). Piénsese, por ejemplo, en las operaciones de absorción y fusión de las grandes multinacionales, o en los casos de desconexión de intereses y de legislaciones entre dos Comunidades Autónomas, colindantes o no, que pudiera propiciar una inidónea ubicación de los grandes establecimientos desde el punto de vista de la ordenación de las obras públicas, las comunicaciones, los transportes o los servicios de interés supraautonómico en el sector o en la zona territorial afectada (pues el comercio no atiende con prevalencia a los lindes administrativos, sino a la obtención de beneficios) o, incluso, que resultasen contradictorios u opuestos los intereses de ambas Comunidades Autónomas en función de la diferenciada 
concepción del comercio, la ordenación del territorio y la protección del medio ambiente. Desde tales puntos de vista, no sobraría (aunque fuese tan sólo en relación a la defensa de la competencia) la opinión de un órgano de la Administración del Estado, supuestamente ajeno al juego de intereses empresariales, administrativos y sectoriales que pudieran latir eventualmente en la instalación de grandes establecimientos.

\section{La intervención de las Comisiones Territoriales de Equipamientos Comerciales}

Finalmente, en la tramitación de la «licencia comercial», la LOCM alude al informe que pudieran emitir las Comisiones Territoriales de Equipamientos Comerciales que se supone pueden crear las Comunidades Autónomas.

El precepto, con independencia de ser supletorio, resulta superfluo, pues tan sólo sirve para orientar a las Comunidades Autónomas (quizá poco adecuadamente, según cabría inferir de lo que a continuación se expone) que todavía no han efectuado la regulación en materia de ordenación comercial al objeto de que, cuando lo hagan, sigan la pauta de algunas de las que ya lo han hecho creando comisiones específicas para informar en materia de comercio. Si bien el legislador estatal se permite aclarar (aun cuando ello también parece innecesario) que el informe que emitan habrá de ser de acuerdo con lo que establezcan las normas autonómicas, creemos que, de una parte, intentando deslindar o llamar la atención sobre el límite competencial y, de otra, recordando la idea del carácter reglado de las autorizaciones.

La idea de creación de tal tipo de Comisión surgió por primera vez en la primitiva Ley catalana 3/1987 (la valenciana, siendo anterior, no hace referencia a ella). El Tribunal Constitucional encontró conforme a Derecho su existencia, declarando que el sometimiento de la solicitud de licencia municipal de instalación o de ampliación de un establecimiento comercial de grandes dimensiones al informe de una Comisión Territorial de Equipamientos Comerciales no es un requisito ausente de lógica ni carente de adecuación al respeto de otros derechos (de otros comerciantes, de los consumidores y de los vecinos de las zonas afectadas) y bienes constitucionales ni, en cualquier caso, supone una carga excesiva o desproporcionada para el solicitante. La composición plural, además, de la mencionada Comisión interviniendo miembros representativos de los sectores afectados, garantiza la idoneidad de su decisión, sin perjuicio de 
que unas supuestas restricciones de la libertad de empresa o unas hipotéticas arbitrariedades puedan ser controladas y, en su caso, reparadas por los Tribunales ordinarios (STC 227/1993) ${ }^{22}$.

Careciendo de otros puntos de referencia, resultaría, pues, sumamente prudente el interpretar que las futuras Comisiones que pudieran crearse (aunque nosotros no las veamos necesarias) ostenten una composición plural y representativa de los sectores afectados (al menos, Administraciones autonómica y local, organizaciones de consumidores y de empresarios) con el fin tanto de ponderar adecuadamente los intereses en juego como el ajuste de la decisión adoptada al conjunto y globalidad del ordenamiento jurídico ${ }^{23}$.

El informe que hubieran de emitir dichas Comisiones se sometería a la regla general prevenida para su emisión en el artículo 83 LRJAP, anteriormente referenciado, bien entendido que el plazo para la emisión del informe y su carácter y signo podrán ser determinados (si así se desea) por la legislación de las Comunidades Autónomas. En otro caso, resultará incidente el expresado artículo 83 LRJAP.

\footnotetext{
${ }^{22}$ PrÑar Mañas (ob. cit., p. 76) recuerda que las Comisiones Provinciales se insertan en la concepción de las fórmulas de participación ciudadana en el funcionamiento de la Administración, a través de la denominada participación orgánica. Nota también (pp. 71-72) que previsiblemente su funcionamiento habrá de interferir en la competencia urbanística local.
}

${ }^{23}$ El problema de las Comisiones Provinciales de Equipamientos Comerciales (también con antecedentes en el Derecho francés), a nuestro entender, radica, de una parte, en la existencia de funciones o tareas que justifiquen su creación y pervivencia y, de otra parte, en la asignación de miembros que, sea a nivel institucional o personal, pueden resultar coincidentes con los que integran las Comisiones de Precios o las Comisiones Provinciales y Regionales de Urbanismo o de Ordenación del Territorio, también integradas en la organización de las Comunidades Autónomas. Una adecuada aplicación del principio de coordinación (art. 103 CE, 3 LRJAP) obligaría a establecer mecanismos de conexión y a evitar duplicidades, aunque, en lo que nosotros conocemos, las Comunidades Autónomas han estado interesadas en la creación de nuevos órganos más que en el aprovechamiento y articulación de los existentes. En tal contexto, quizá nosotros debiéramos recordar que la Carta Europea de Ordenación del Territorio, aprobada el 23 de mayo de 1983 por la Conferencia Europea de Ordenación del Territorio, define tal clase de ordenación como la expresión espacial de la política económica, social, cultural y ecológica de toda la sociedad. Por tanto, si la instalación de un gran establecimiento se inserta en el denominado urbanismo comercial que ha de dirigir y controlar la política económica local y regional, resulta difícil comprender cómo, en lugar de adaptar las Comisiones autonómicas competentes en materia de urbanismo y medio ambiente (lo que pudiera hacerse incluso en función de la naturaleza de los asuntos a tratar), se opta por crear nuevas comisiones con una visión muy parcial y desgajada de la ordenación territorial. El tema se complica, además, si se tiene en cuenta que además de la Comisión Provincial de Equipamientos Comerciales habrán de intervenir también en la autorización las Comisiones de Urbanismo y Medio Ambiente de la misma Administración autonómica, sea en la tramitación del Plan urbanístico, sea en la licencia de apertura, lo que podría generar contradicciones o puntos de vista diversos que resultarían injustificables en la intervención tutelar de la misma Administración (véase, en cuanto al trámite, lo consignado en la siguiente nota 25 ). 


\section{E. La «licencia comercial» obtenida por silencio positivo}

Tomando como punto de referencia el RDL 1/1986, la Recomendación 90/246 CEE y la Ley italiana 241/1990, la LRJAP invirtió o cambió en apariencia la regla del silencio negativo que anteriormente consagraba la legislación española sobre procedimiento administrativo. La vigente norma jurídica prevé la estimación de las peticiones presentadas por los ciudadanos mediante el transcurso del plazo previsto para cada procedimiento y, en su defecto, en el de 3 meses (art. 42.2 LRJAP) sin perjuicio de su eventual interrupción (arts. 77, 83.3 LRJAP) o de su prórroga motivada (arts. 42.2, 49, 54.1.e LRJAP).

El plazo para la tramitación de la «licencia comercial» debiera, pues, ser señalado por la legislación de las Comunidades Autónomas que se dicte en adaptación a la LOCM (a título de ejemplo, la Ley valenciana señala un plazo de dos meses y la gallega de tres meses). De no hacerse así, se aplicará el plazo supletorio de tres meses consignado por la LRJAP, transcurrido el cual puede entenderse obtenida la «licencia comercial» mediante silencio positivo. La regla legal contenida en el artículo 43 LRJAP establece la estimación de la pretensión cuando se trate de solicitudes cuya estimación habilitaría al solicitante para el ejercicio de derechos preexistentes [art. 43.2.b)] y, en particular, para la instalación de centros de trabajo [43.2.a)], lo que entronca directamente con el significado de la autorización que ahora cuestionamos.

Pero no basta el mero transcurso del plazo para asumir obtenida definitivamente la autorización, pues los interesados que deseen hacer eficaz frente a terceros y frente a la propia Administración el resultado del silencio positivo, deben interesar lo que se denomina legalmente una certificación del acto presunto (art. 44 LRJAP), acreditativa del signo del silencio y de los efectos generados. Dicha certificación debe emitirse por la Administración en un plazo de 20 días. De no hacerse así, con independencia de la responsabilidad del funcionario encargado de la tramitación (el ciudadano ostenta un derecho subjetivo a exigirla - arts. 35.j), 41, $42.3,44.3$ y 79.2 LRJAP-), el acto puede hacerse igualmente eficaz - según la Ley - con la exhibición de la solicitud de la certificación (art. 44.3 LRJAP).

Mas, no basta tampoco el mero transcurso del plazo de emisión de la certificación de acto presunto para asumir que se ha obtenido la «licencia comercial». En primer lugar, debe advertirse que la regla del silencio positivo establecida de modo general, se asienta con carácter subsidiario, es 
decir, cuando la normativa reguladora de cada procedimiento no establezca el silencio negativo [art. 43.2.c) LRJAP]. Y no han sido pocos los procedimientos en los se ha dado la vuelta a la regla legal de la estimación por silencio. Incluso transcurrido el plazo de adecuación a la Ley (DA 3. ${ }^{\mathrm{a}}$ LRJAP), se siguen apuntando procedimientos en los que el silencio debe entenderse como desestimatorio de las solicitudes formuladas. Por tanto, debe esperarse a lo que cada Comunidad Autónoma determine en la normativa que dicte adaptándose a la LOCM, sin perjuicio de que el panorama actual sea consecuente con la regla general diseñada por la legislación estatal básica (la todavía vigente Ley valenciana reconoce expresamente el silencio positivo en el otorgamiento de la autorización y, en su sintonía, la Ley andaluza reconocía el signo positivo del informe no emitido en plazo).

En segundo lugar, y para el caso en que la legislación de las Comunidades Autónomas confirme la regla del silencio positivo (o no signifique nada al respecto), debe tomarse en consideración que nuestra jurisprudencia ha venido proclamando tradicionalmente, con una doctrina no exenta de diversos matices, que no se pueden adquirir a través del silencio positivo facultades o derechos en contra del ordenamiento jurídico (entre otras, SSTS de 23 de julio, 25 de noviembre y 15 de diciembre de 1992 —RRA 6.584, 9.331 y 9.839 - 13 de abril, 18 de mayo, 20 y 22 de julio y 28 de diciembre de 1993 -RRA $2.675,3.783,5.600,5.815$ y 10.045 - y 12 de julio, 29 de septiembre y 26 de octubre de 1994 - RRA $5.538,7.150$ y $7.789-)$, al menos y en todo caso cuando la contravención fuere patente o notoria. De ahí que el artículo 62.1.f) LRJAP impute un vicio de nulidad a los actos administrativos emitidos mediante silencio y que permitan adquirir tales facultades o derechos. En tal contexto debe ponderarse que si bien el acto nulo carece de validez (la nulidad es inconvalidable) y eficacia, cuando sea la Administración la interesada en declarar y reconocer la nulidad deberá acudir a un procedimiento de revisión de oficio (art. 102 LRJAP), en su caso y si procediese, con secuelas indemnizatorias (art. 142.4 LRJAP) ${ }^{24}$.

\footnotetext{
${ }^{24}$ Nota explicativa introducida en trámite de corrección de erratas: La reforma de la LRJAP llevada a cabo por la Ley $4 / 1999$ ha alterado no sólo la referencia a los preceptos de dicha ley que se citan en el presente trabajo, sino a su contenido material. Particularmente y en relación a lo expuesto, interesa llamar la atención sobre la desaparición del certificado de acto presunto, que tan temido era por los funcionarios (la eficacia del silencio puede hacerse valer ahora con el denominado certificado acreditativo del silencio - art. 43.5-). Otra modificación sustancial viene constituida por la novedosa regulación introducida en materia de duración de expedientes, informes que han de ser emitidos en ellos y causas de suspensión del procedimiento (fundamentalmente, art. 42). Finalmente debe llamarse la atención sobre el mantenimiento (a pesar de las cualificadas críticas doctrinales) de la regla del silencio positivo (art. 43.2), quizá más como instrumento de presión frente a la Administración que como regla efectiva para la obtención de autorizaciones administrativas [den-
} 


\section{REFERENCIA A OTRAS AUTORIZACIONES ADMINISTRATIVAS}

El mismo precepto que establece y regula la «licencia comercial» establece su compatibilidad con cualesquiera otras autorizaciones que entiendan las Comunidades Autónomas pueden imponer y exigir en supuestos relacionados con la actividad comercial (art. 6.1 LOCM).

A tenor de lo que se ha expuesto en anteriores líneas, ningún inconveniente cabe oponer a tal previsión desde el punto de vista jurídico, pues ya hemos visto que, según nuestro Tribunal Constitucional, compete a los diversos poderes públicos el establecer, cada uno dentro de su competencia, los límites y requisitos a los que debe sujetarse la instalación de establecimientos o el ejercicio de actividades (siempre con el natural límite de que los medios utilizados sean proporcionados al fin perseguido y que se trata de obtener). Nótese, no obstante, que nosotros en anteriores líneas [apartado 1.a)], y ante la ausencia de normas puntuales que impongan una concreta coordinación de procedimientos, nos hemos mostrado adversos

tro del campo del urbanismo y aunque con fuerza expansiva hacia otros ámbitos, según ha hecho notar alguna resolución judicial, debe recordarse que la jurisprudencia sigue manteniendo la imposibilidad de que las licencias contrarias al ordenamiento juridico sean obtenidas mediante silencio (en algunos casos se alude a la imposibilidad de obtener facultades pero en otros, con evidencia, a la imposibilidad de obtener una licencia contra legem). En esta linea de entendimiento, se recordará también que el redactor del Texto Refundido de la Ley del Suelo de 1992 (quizá excediendo de la autorización otorgada por el legislador de la Ley 8/1990) sustituyó la referencia a la imposibilidad de adquirir facultades mediante silencio que contenía el Texto Refundido de 1976 (art. 178.3) por la imposibilidad de adquirir licencias mediante silencio. Para nosotros, la diferencia es ciertamente relevante, pues, en el primer caso la autorización se obtenía, aunque no las facultades derivadas de ella, siendo dicha autorización un acto nulo de pleno Derecho (art. 62.1.f LRJAP) que obligaba a la Administración a tramitar el correspondiente procedimiento de revisión y, en su caso, a afrontar las secuelas indemnizatorias. En el segundo caso, simplemente, lo que no se obtiene es la licencia contraria al ordenamiento (si hay contravención del ordenamiento el silencio es negativo). Hoy, a pesar del retorno a la expresión sustentada por el texto de 1976 (y sin perjuicio de lo que establezca cada legislación autonómica al respecto), debe ponderarse la consolidada doctrina jurisprudencial existente impidiendo obtener licencias contrarias al ordenamiento a través de la técnica del silencio, que no resulta discutida doctrinalmente en su pertinencia, a pesar de la inseguridad jurídica que genera respecto del administrado, que no puede conocer verdaderamente si tiene otorgada o denegada una licencia mediante silencio. Fuera del ámbito del urbanismo se halla también descafeinada la doctrina del silencio positivo en materia de autorizaciones. Algunos legisladores han plasmado normativamente la regla jurisprudencial más allá del urbanismo (es el caso del legislador aragonés en la Ley $7 / 1999$, de régimen local de Aragón (art. 193.2.5. ${ }^{2}$ )), que establece la regla del silencio positivo en todas las licencias, tan sólo en la medida en que su contenido no sea contrario al ordenamiento jurídico. Pero, en general, la jurisprudencia tampoco es proclive a admitir que se obtengan autorizaciones por silencio cuando perciba cualquier clase de contravención en el ordenamiento, en unos casos, por agarrarse a la existencia de cualquier tipo de incumplimiento por parte del administrado $o$ a la denuncia de defectos en el procedimiento, en otros, como podría — quizá- ser el caso de la autorización comercial, por entender que han de fiscalizarse aspectos que no están todos ellos reglados y que, por tal motivo, no puede entenderse que se entienda otorgada la autorización a través de la técnica del silencio]. 
a convertir la instalación de un establecimiento o el ejercicio de una actividad en una carrera de obstáculos en la que puedan superarse unos sí y otros no, desconociendo al final cuál va a ser el resultado del intento efectuado.

Si la «licencia comercial» podría haber resultado innecesaria, pudiéndose tutelar el bien jurídico protegido a través de otros mecanismos y actuaciones (aplicando los Ayuntamientos la normativa correspondiente o coordinando las competencias de la Comunidad Autónoma al momento de aprobar o de informar los instrumentos de planeamiento o, incluso, al momento de tramitar la licencia de apertura - de hecho, y según el RAMINP arts. 31 y ss.-, todas las aperturas de establecimientos jurídicamente calificables como molestos o afectados por el meritado Reglamento - lo son, sin duda, todos los grandes establecimientos- están sujetas a la intervención e informe de la Comunidad Autónoma-), con mayor razón resultaría absurdo que dentro del mismo Departamento competente en materia de comercio viniesen a exigirse varias autorizaciones sobre la misma materia cuando, para el mismo sujeto, todos los requisitos administrativos exigibles pudieran (y quizá debieran) ser ponderados, analizados y controlados adecuadamente a través de un único expediente y una sola autorización ${ }^{25}$.

${ }^{25}$ CASES y PONS apuntan que la LOCM implica un protagonismo de la Administración autonómica en detrimento de la local (ob. cit., p. 19), dado que la autorización comercial es independiente de la urbanística (así lo expresó el Consejo de Estado francés en Resolución de 10 de junio de 1983) (ob. cit., p. 62), constituyendo un problema el que la Administración local carezca de competencias en materia de comercio (ob. cit., p. 72). No obstante, citan la Sentencia del TSJ de Cataluña de 19 de febrero de 1988, confirmada por la del Tribunal Supremo de 28 de septiembre de 1993, en la que se declaró acomodado al ordenamiento el Plan del comercio alimentario aprobado por el Ayuntamiento de Barcelona, a pesar de ordenar y regular claramente aspectos «comerciales». Por nuestra parte, creemos que no existe tal problema competencial, pues los Ayuntamientos, a la hora de elaborar los planes, deben recoger multiplicidad de normativas y criterios sectoriales, siendo uno más el atinente a los criterios comerciales establecidos por la Comunidad Autónoma (al igual que al otorgar licencias deben comprobar el cumplimiento de tales normativas y recibir diversidad de informes, vinculantes o no, de otras Administraciones). La novedosa autorización autonómica no ha quedado claro en el modo y momento en que deba ser otorgada por cada Comunidad. La Ley catalana 1/1997 la ha diseñado con anterioridad a cualquier otra autorización precisa para la instalación. En otro contexto, la Ley castellano-leonesa $2 / 1996$ ha decidido insertarla extrañamente en trámites administrativos previos, como lo es el procedimiento de aprobación de instrumentos de planeamiento (pues la Ley autonómica obliga a que toda «licencia comercial» lleve aparejada la tramitación del instrumento de planeamiento que corresponda en función de la clase de suelo) y tras la fase de aprobación inicial. Sin embargo, a nuestro entender, tal previsión complica todavia más el problema desde el punto de vista juridico, pues aunque formalmente se intente respetar (y asi se declare -art. 9.4-) el procedimiento de aprobación de los planes (aun pudiendo alterarlo, pues los artículos 40 al 43 del TRLS de 1976 constituyen legislación supletoria; de ahi que la STC 61/1997 declarase la inconstitucionalidad, entre otros, de los arts. 114 a 116 del TRLS aprobado por RDLeg 1/1992), en realidad se trastoca sustancialmente y de manera anómala dicho procedimiento (además de afectarse, igualmente de manera anormal, el funcionamiento de las entidades locales), primero, por hacer depender el planeamiento local de unos condicionantes externos imprevistos, pues 
No obstante, ahí está la regulación legal y cada Comunidad Autónoma hará de ella lo que entienda más conveniente en función del interés público que crea deba tutelar y dar cumplimiento. A nosotros debe bastarnos ahora el recordar - y con ello finalizamos - que mientras la Administración del Estado o la de las Comunidades Autónomas no establezcan procedimientos coordinados para la obtención de autorizaciones administrativas al objeto de instalar establecimientos o ejercer actividades, o mientras no aprueben regulaciones sobre la relación y el orden de obtención de tales autorizaciones, hoy día, un eventual orden de prelación en la obtención de las mismas, habrá de tener en cuenta que, con normalidad, las autonómicas, al igual que las estatales, habrán de ser anteriores a las locales, según cabe inferir de la misión asignada a cada una de ellas, así como del contenido del artículo 2 del RD 2.187/1978 - RDU-, sin perjuicio de que, dentro de las locales, el Reglamento de Servicios (art. 22.3) haya previsto la licencia de apertura como previa o anterior al permiso de obras, y sin perjuicio también de que ambas se puedan comprobar a través de la de primera ocupación (art. 1.10 RDU). Ello, con independencia de que en la jurisprudencia de nuestro Tribunal Supremo, buscando siempre la idea de justicia para cada caso concreto, puedan hallarse soluciones para todos los gustos, existiendo - aunque pocas - referencias sobre la validez de la anterioridad de los permisos locales condicionados a la obtención de otros de otras Administraciones, o sobre la procedencia de las autorizaciones simultáneas, o en relación a la posibilidad de alterar el orden de las autorizaciones o, incluso - aunque tales casos ya son más extraños-, al entendimiento de que, cuando han de proceder de una misma Administración, el otorgamiento de una implica entender obtenida otra.

el plan redactado pudiera afectar a más aspectos que el atinente tan sólo a la instalación del gran establecimiento (piénsese además en la necesaria articulación con el instituto de suspensión de licencias regulado en el artículo 102 TRLS92, hoy, de nuevo artículo 27 TRLS76, que quedaría notablemente afectado en el cómputo de sus plazos - recuérdese que también ha de informar la Administración del Estado a través del Tribunal de Defensa de la Competencia-); segundo, porque con normalidad el Plan habrá de volver a la Comunidad Autónoma tras la aprobación provisional y para la aprobación definitiva (118 TRLS92, 41 TRLS76), debiendo ser examinado en todos sus aspectos y en particular en lo atinente al ejercicio de competencias autonómicas (SSTS de 3, 6, y 28 de febrero y 25 de abril de 1994 - RRA $1.025,1.029,1.098$ y 2.011 - 30 de enero, 25 de abril y 25 de octubre de 1991 -RRA $616,3.430$ y 7.545 , etc.), lo que convierte el anterior trámite de otorgamiento de la «licencia comercial» en redundante, sino en inútil (con independencia de que un diferenciado órgano, también con competencias en materia de urbanismo comercial, pudiera no compartir el criterio del otro); y tercero, en la medida en que al momento de tramitar el Plan no se conocerán todavía aspectos de la instalación que podrian resultar esenciales desde el punto de vista del comercio y que no precisarán ser aportados hasta el momento de tramitar la licencia de apertura. 